\title{
Phytochemistry, GC-MS Analysis, Antioxidant and Antibacterial Potentials of Limonene Isolated from Pericarp of Citrus sinensis
}

\author{
James Hamuel Doughari", Musa Jamila Bazza \\ Department of Microbiology, School of Life Sciences, Moddibo Adama University Technology, Yola, Nigeria \\ Email address: \\ jameshamuel@yahoo.com (J. H. Doughari),jameshamuel@mautech.edu.ng (J. H. Doughari) \\ ${ }^{*}$ Corresponding author
}

To cite this article:

James Hamuel Doughari, Musa Jamila Bazza. Phytochemistry, GC-MS Analysis, Antioxidant and Antibacterial Potentials of Limonene Isolated from Pericarp of Citrus sinensis. International Journal of Microbiology and Biotechnology. Vol. 5, No. 1, 2020, pp. 22-27. doi: $10.11648 / j . i j m b .20200501 .14$

Received: January 10, 2020; Accepted: January 27, 2020; Published: February 19, 2020

\begin{abstract}
Limonene is essential oil isolated from pericarp of $C$. sinensis it is well known for its antimicrobial and antiseptic activities. Limonene has many medicinal properties and is widely used for the treatment of stomach aches, breast cancer, and as tonic for the digestive system, immune system and skin. It is also used to treat and prevent vitamin deficiencies, colds, flu, and typhoid fever, and to help fight viral and bacterial infections. The aim of this work was to determine the composition, antioxidant and antibacterial properties of limonene from pericarp of $C$. sinensis. Limonene from C. sinensis pericarps were extracted using steam distillation method. Phytochemical screening of the extracts revealed the presence of terpenoids and limonene in the extracts while GC/MS analysis showed highest percentage of limonene (96\%). Result of antioxidant activity determination showed that limonene demonstrated strong scavenging activity $(92.42 \%)$. Antimicrobial activity of the limonene extracts was evaluated by agar well method against $S$. aureus, S. pyogenes, $P$. aeruginosa, $S$. typhi while MIC and MBC were determined using the agar well dilution technique. Result showed that limonene extract exhibited an MIC of $200 \mathrm{mg} / \mathrm{ml}$ and MBC range of 300-400 mg/ml against all the isolates. The antibacterial effects of the extracts suggest their possible inclusion as candidate agents for development of chemotherapeutic agents against infection caused by the bacterial pathogen s tested.
\end{abstract}

Keywords: Limonene, GS-MS Analysis, Phytochemical, Antioxidant, Antibacterial Activity

\section{Introduction}

Citrus fruits have been collected and used by man for centuries for medicinal, herbal and agricultural purposes [1]. The sub-genus Citrus (Swingle), family Rutaceae and subfamily Aurantioideae is of three types Citrus, Fortunella (Kumquat) and Poncirus trifoliata. Citrus sinensis a member of this family and a major source of vitamins, especially vitamin C, sufficient amount of calcium, potassium, thiamine, niacin and magnesium [2]. Citrus is widely grown in Nigeria and many other tropical and subtropical regions [3]. In terms of volume in production, citrus ranks after banana as the world second fruit crop with more than 108 million tons [4]. Citrus sentences pericarp is derived from the fruit of Citrus silences [5], the plant is called sweet orange (English) and is locally called Lemon-zakat (Hausa).
Sweet orange constitute about $60 \%$ of the total citrus world production. Pericarp represent between $50-60 \%$ of total weights of the products. In the citrus industry, emphasis is laid only on orange fruits. The fruits are harnessed and marketed fresh or as processed canned juice while fruits pericarp produced in great quantities during the processing are mainly discarded as waste. If not processed further, it becomes waste, producing odor, soil pollution, harborage for insect and can lead to environmental pollution. Citrus sentences essential oil called "Limonene" has been reported to effectively prevent development of abnormal growths on the skin [6]. It is also well known for its antimicrobial, antioxidant and antiseptic activities [7]. The compound has been employed in nutrition, health applications and cosmetic products. Limonene is rapidly absorbed in the gastrointestinal tract in humans [8-10]. D-limonene is also used in food 
manufacturing and medicines, e.g. as a flavoring to mask the bitter taste of alkaloids, and as a fragrant in perfumery and as a botanical insecticide [11-13]. Being an excellent solvent of cholesterol, d-limonene has been used clinically to dissolve cholesterol-containing gallstones. Because of its gastric acid neutralizing effect and its support of normal peristalsis, it has also been used for the relief of heartburn [14]. Vive et al. [15] reported anti typhoid activity of aqueous extract of Citrus sinensis pericarp. The aim of this work therefore was to determine the composition, antioxidant and antibacterial properties of limonene from pericarp of $C$. sinensis.

\section{Results}

\subsection{Phytochemical Analysis of Limonene Extracts}

Result of phytochemical analysis of limonene extracts of Citrus sinensis are shown in (Table 1). Results showed that limonene contained terpenoids.

\subsection{Gas Chromatography-mass Spectrometry (GC/SM) Analysis for Detection of Limonene Extracts}

Result of GC-MS of the pericarp extracts is shown in Figure 1. Result showed that limonene was the key element in the essential oil of Citrus sinensis. Result also revealed that limonene $(96 \%)$ was the highest chemical component of the extract followed by D-limonene (91\%) (Table 2).

\subsection{Antioxidant Activity of Limonene Extracts}

Result of antioxidant activity indicated that the limonene extracts exhibited potential free radical scavenging activity (Table 3). Result also showed that the limonene extracts showed radical scavenging activity in the range of 89.90 $92.42 \%$.

\subsection{Antibacterial Activity of Limonene Extracts}

Result of antibacterial activity of limonene extracts of Citrus sinensis against some pathogenic Gram positive and Gram negative bacterial isolates (Tables 4 and 5) showed that limonene extracts (Table 4) produced inhibition activity against Staphylococcus aureus, Streptococcus pyogenes, Pseudomonas aeruginosa, and Salmonella typhi with diameters of zone of inhibition ranging between 7.0-18.6 mm with the highest inhibition activity against Streptococcus pyogenes (diameter of zone of inhibition $18.6 \mathrm{~mm}$ ).

Results of MIC and MBC determination of limonene extracts are shown in Table 5. Result showed that limonene extracts exhibited MIC values of $200 \mathrm{mg} / \mathrm{ml}$ while MBC values ranged between $300-400 \mathrm{mg} / \mathrm{ml}$ on the isolates tested. Result also showed that the lowest MBC value of $300 \mathrm{mg} / \mathrm{ml}$ was demonstrated against Streptococcus pyogenes while the highest $\mathrm{MBC}$ value of $400 \mathrm{mg} / \mathrm{ml}$ was exhibited against Salmonella typhi (Table 5).

Table 1. Phytochemical analysis of limonene from pericarp extracts of Citrus sinensis.

\begin{tabular}{ll}
\hline Phytoconstituent & Limonene extracts \\
\hline Alkaloid & - \\
Flavonoid & - \\
Steroid & - \\
Terpenoid & + \\
Saponin & - \\
Tannin & - \\
Phenol & - \\
\hline
\end{tabular}

Key: $+=$ present, $-=$ absent.

Abundance

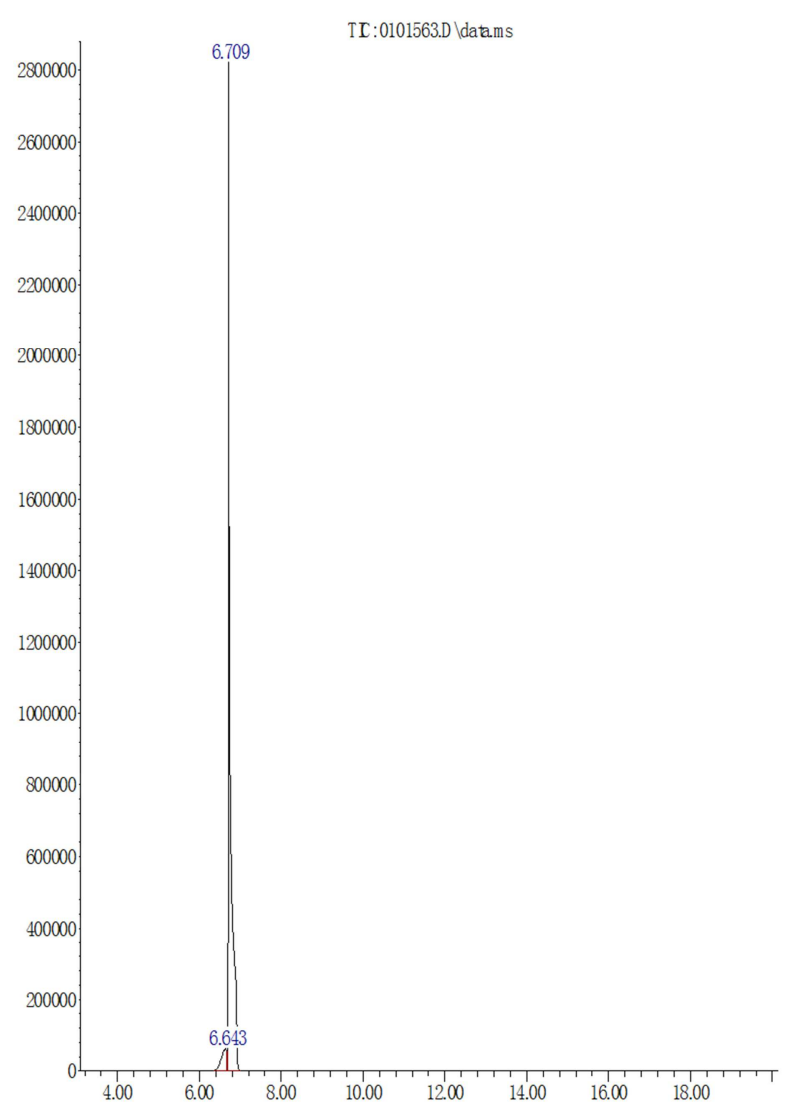

Tine-

Figure 1. Gas chromatogram of pericarp extracts of Citrus sinensis showing the limonene constituents.

Table 2. Identified chemical constituents of the limonene from pericarp extracts of Citrus sinensis.

\begin{tabular}{|c|c|c|c|c|c|c|}
\hline Pk\# & RT & Area \% & Library/ID & Ref\# & CAS\# & Qual \\
\hline \multirow[t]{3}{*}{1} & 6.643 & 5.89 & C:IDatabaselNBS75K. L Limonene & 6647 & 000138-86-3 & 96 \\
\hline & & & Cyclohexene, 1-methyl-4-(1-methyle thenyl)-, (.+/-.)- (terpenoid) & 6633 & 007705-14-8 & 90 \\
\hline & & & Cyclohexene, 1-methyl-4-(1-methyle thenyl)-, (S)- (terpenoid) & 65806 & 005989-54-8 & 90 \\
\hline \multirow[t]{3}{*}{2} & 6.709 & 94.11 & C:IDatabaselNBS75K. L Limonene & 6647 & 000138-86-3 & 96 \\
\hline & & & D-Limonene & 65790 & 005989-27-5 & 91 \\
\hline & & & D-Limonene & 6664 & 005989-27-5 & 90 \\
\hline
\end{tabular}


Table 3. Antioxidant activity of limonene extract pericarp of Citrus sinensis.

\begin{tabular}{lll}
\hline Concentration $(\boldsymbol{\mu g} / \mathbf{m l})$ & Limonene extracts $(\%)$ & Standard $($ Ascorbic acid) $(\%)$ \\
\hline 20 & 89.90 & 89.90 \\
40 & 90.52 & 90.52 \\
60 & 90.85 & 92.42 \\
80 & 91.79 & 93.37 \\
100 & 92.42 & 94.94 \\
\hline
\end{tabular}

Table 4. Antibacterial activity of limonene pericarp extracts of Citrus sinenesis.

\begin{tabular}{|c|c|c|c|c|c|c|c|c|c|c|c|c|}
\hline \multirow{3}{*}{ Test Bacteria } & \multicolumn{12}{|c|}{ Average zone of inhibition (mm) } \\
\hline & \multicolumn{12}{|c|}{ Concentration $\mathrm{mg} / \mathrm{ml}$} \\
\hline & 5 & 25 & 50 & 75 & 100 & 125 & 150 & 200 & 250 & 300 & 350 & 400 \\
\hline $\begin{array}{l}\text { Staphylococcus aureus } \\
\text { Streptococcus pyogenes } \\
\text { Pseudomonas aeruginosa } \\
\text { Salmonella typhi }\end{array}$ & $\begin{array}{l}- \\
- \\
-\end{array}$ & $\begin{array}{l}- \\
- \\
-\end{array}$ & $\begin{array}{l}- \\
- \\
-\end{array}$ & $\begin{array}{l}- \\
- \\
-\end{array}$ & $\begin{array}{l}- \\
- \\
-\end{array}$ & $\begin{array}{l}- \\
- \\
-\end{array}$ & $\begin{array}{l}- \\
- \\
-\end{array}$ & $\begin{array}{l}8.00 \\
8.60 \\
7.00 \\
7.00\end{array}$ & $\begin{array}{l}8.00 \\
10.3 \\
7.33 \\
7.30\end{array}$ & $\begin{array}{l}9.63 \\
12.33 \\
10.00 \\
9.33\end{array}$ & $\begin{array}{l}13.33 \\
13.66 \\
10.83 \\
10.33\end{array}$ & $\begin{array}{l}18.00 \\
18.60 \\
14.33 \\
14.00\end{array}$ \\
\hline
\end{tabular}

Key: = - = no inhibition.

Table 5. MIC and MBC of limonene from pericarp extracts of Citrus sinensis.

\begin{tabular}{lll}
\hline Organism & MIC $(\mathbf{m g} / \mathbf{m l})$ & MBC $(\mathbf{m g} / \mathbf{m l})$ \\
\hline Staphylococcus aureus & 200 & 350 \\
Streptococcus pyogenes & 200 & 300 \\
Pseudomonas aeruginosa & 200 & 350 \\
Salmonella typhi & 200 & 400 \\
\hline
\end{tabular}

\section{Discussion}

Citrus sinensis pericarps commonly treated as agroindustrial wastes are potential sources of valuable secondary metabolites [26]. Result obtained from this study revealed that both limonene extracts from the pericarp of Citrus sinensis contained terpenoids only. This finding is at variance with results by Okwu et al. [16], who screened phytochemicals of five Citrus species and revealed the presence of saponins, tannins, flavonoids, alkaloids and phenols. The terpenoids as well as the other phytochemical compounds are known to be biologically active and therefore aid the antimicrobial activities of the plants. Terpenoids observed in the ethanol extracts from this study was earlier reported to be involved in membrane disruption by the lipophilic compounds [17].

GCMS analysis revealed that limonene was the major (96\%) chemical compound in the pericarp extracts investigated. Similar result conducted by Svoboda and Greenaway [18] reported the key chemical constituent of Citrus essential oils as limonene ranging between 32 - 98\%. Limonene is well known for its antimicrobial and antiseptic activities. The compound has been has found important application in nutrition, health and in cosmetic products. Dlimonene is used in food manufacturing, in medicines and as flavor and fragrance additive in perfumes, soaps, chewing gums, and beverages. [11, 14]. For instance, linalool $(1,6-$ Octadien-3-ol, 3,7 dimethyl (72\%) is used as flowery aroma, in $60-80 \%$ of perfumery, and cleaning agents including soaps detergents, shampoo lotion and mosquito repellent products [19]. It has however been reported that different Citrus species may have different chemical constituents due to different genetic characteristics [20].

Antioxidant analysis revealed that limonene extracts of Citrus sinensis have scavenging activity ranging from 89.90 92.42\% Toscano-Garibay et al. [19] also reported that Citrus peel oils have strong potential to reduce DPPH to DPPH-H (83-91\%). Limonene was major constituent of citrus pericarp oil having antioxidant potential equivalent to that of strong antioxidant [21]. Furthermore, essential oil of many Citrus sinensis which enhanced the singlet oxygen production has high levels of limonene and low levels of linalool, a monoterpene alcohol [22]. Natural antioxidants play a key role in health maintenance and prevention of the chronic and degenerative diseases, such as atherosclerosis, cardiac and cerebral ischemia, carcinogenesis, neurodegenerative disorders, diabetic pregnancy, rheumatic disorder, DNA damage and ageing $[23,24]$.

The demonstration of antibacterial activity of the pericarp extracts of Citrus sinensis against some pathogenic Gram positive and Gram negative bacterial isolates is an indication that the compound possessed a broad spectrum activity. This means that it can be employed in the treatment of a wide range of pathogenic diseases ranging from urinary tract infections, otitis media, diarrhea, gastroenteritis and pneumonia caused the bacterial pathogens investigated in this study. Results of MIC $(200 \mathrm{mg} / \mathrm{ml})$ and MBC (300-400 $\mathrm{mg} / \mathrm{ml}$ ) of the limonene extracts of the pericarp of Citrus sinensis showed that when further purified will potentially exhibit very high antibacterial activity The MIC values obtained are much higher than that obtained by Lawal et al. (5), Dhiman et al. [25] and Jwanny et al. [26] against Salmonella typhi, Salmonella paratyphi, Aeromonas hydrophila and Pseudomonas aeruginosa. The disparity in activity with results of this study could be due to differences 
in the pytochemical composition of plant samples investigated, extraction methods used, environmental factors or genetic factors.

\section{Materials and Methods}

\subsection{Collection and Processing of Citrus Fruits}

Three hundred (300) ripe fruits of Citrus sinensis (sweet orange) that are free from insect infestation and other kinds of damage were collected from Jimeta Modern Market during the month of July and August 2016. The plant was identified by confirmed in the Department of Botany, Moddibo Adama University Technology Yola, Nigeria.

\subsection{Extraction of Limonene from Citrus Sinensis Pericarp}

Limonene was extracted by steam distillation for 4-5 h. The Citrus sinensis pericarp were placed in the round bottom flask and filled with water to about three quarter full. The distillation apparatus was set up and connected to the flask. Water was filled into the trap arm to allow the limonene condense on the water layer. The heating mantle supplied the needed heat and as the water in the flask boiled, steam carrying the limonene through the neck of the flask condensed on the surface of the condenser onto the water on the graduated trap arm. This was followed by draining off of the limonene which was subsequently dried over anhydrous sodium sulphate (BDH) [27].

\subsection{Phytochemical Screening of Limonene Extracts}

Phytochemical component of the limonene extracts was determined using standard procedures as earlier described [28-30].

\subsection{Gas Chromatography-Mass Spectrophotometry (GC- MS) Analysis of Limonene}

The chromatographic procedure was carried out using a 7890A GC system (Agilent Technologies) equipped with a mass selective detector (MSD) 5975C (Agilent Technologies), injector series model $7683 \mathrm{~B}$ and HP-5MS capillary column $(30 \mathrm{~m} \times 0.320 \mathrm{~mm}, 0.25 \mu \mathrm{m}$ film thickness). The temperature of the column was maintained at $35^{\circ} \mathrm{C}$ for $1 \mathrm{~min}$ and then raised to $100^{\circ} \mathrm{C}$ per min for a holding time of $3 \mathrm{~min}$. Finally, the temperature of the injection port was maintained at $2200{ }^{\circ} \mathrm{C}$ and that of the detector at $2500^{\circ} \mathrm{C}$ for 3 min holding time. This was adapted in order to prevent excess long chain fatty acids from accumulating on the GC column. Helium was the carrier gas. The following parameters were maintained: Pressure, 112.0 $\mathrm{kPa}$, Total flow, $32.7 \mathrm{ml} / \mathrm{min}$, Column flow, $1.90 \mathrm{ml} / \mathrm{min}$ and Linear velocity, $50 \mathrm{~cm} / \mathrm{sec}$. The chromatographic effluent was then analyzed by the MSD [31].

\subsection{Determination of the Antioxidant Activity of Limonene}

The antioxidant activity of the limonene compound was determined by measuring the stable 1,1-diphenyl-2-picryl hydrazyl radical (DPPH) free radical-scavenging activity of the extracts $[31,32]$. Various concentrations $(20,40,60,80$ and $100 \mu \mathrm{g} / \mathrm{ml}$ respectively) of each extract was added to equal volume, to methanol solution of DPPH $(100 \mu \mathrm{m})$ in separate test tubes and allowed to react for $15 \mathrm{~min}$ at room temperature, after which, the absorbance was recorded at 517 $\mathrm{nm}$. The experiment was repeated for three times. Ascorbic acid was used as standard controls. IC50 values denote the concentration of sample, which is required to scavenge $50 \%$ of DPPH free radicals.

\subsection{Antibacterial Activity of Limonene}

\subsubsection{Source of Test Bacteria}

Four (4) different clinical isolates (2 Gram positive; Staphylococcus aureus, Streptococcus pyogenes, and 2 Gram negative; Salmonella typhi, Pseudomonas aeruginosa,) were collected from the Microbiology Laboratory, Federal Medical Centre Yola, Adamawa State, Nigeria. The isolates were subcultured (on Cystine lactose electrolyte -deficient agar, Blood agar, Kligler iron agar and Cetrimide agar) for purity and further identified using standard biochemical tests [33] at the Microbiology Laboratory of the Department of Microbiology, Modibbo Adama University of Technology, Yola, Nigeria.

\subsubsection{Antibacterial Activity of Limonene Extracts}

Antimicrobial activity of the limonene extract was assessed using agar well diffusion method. Each labeled Mueller-Hinton agar plate was uniformly seeded with a test organisms $\left(10^{8} \mathrm{CFU} / \mathrm{ml}\right)$ by means of sterile swab rolled in suspension and streaked on the plate surface. Wells of $6 \mathrm{~mm}$ diameter and $5 \mathrm{~mm}$ depth was made on the solid agar using a sterile glass borer [31, 34, 35]. Approximately $100 \mu / \mathrm{ml}$, of the various concentrations $(5,25,50,75,100,125,150,200$, $250,300,350$ and $400 \mathrm{mg} / \mathrm{ml}$ ) were dropped into each well to fullness. The plate was allowed to dry for 20-30 min and then incubated at $37^{\circ} \mathrm{C}$ for $24 \mathrm{~h}$. After incubation, antimicrobial activity was measured by measurement of the diameter of zone of inhibition $(\mathrm{mm})$ around the culture isolates.

\subsection{Determination of Minimum Inhibitory Concentrations (MIC) and Minimal Bactericidal Concentration (MBC) of Limonene}

Sterile inoculating loop was used to cut the clear zones produced during the tests for antibacterial activities and streaked in fresh chocolate agar plates. The plates were incubated at $37^{\circ} \mathrm{C}$ for $24 \mathrm{~h}$. Concentration that inhibited visible growth was regarded as the MIC. Isolates at extract concentrations that did not show visible growth were further subcultured onto plates of Mueller Hinton agar or chocolate agar as the case may be and further incubated $37^{\circ} \mathrm{C}$ for $24 \mathrm{~h}$. After the incubation period, absence of growth on the plates was interpreted as bactericidal action (MBC) $[36,37]$. 


\section{Conclusions}

In this present study, Citrus sinensis pericarp demonstrated the presence of high percentage of limonene. Investigation also revealed that the limonene contains terpenoids and exhibited strong antioxidant and antibacterial potential. This suggests that extracts are candidate agents for development against infection caused by the pathogens tested. Further bioactive activity against a wider range of pathogenic bacteria and fungi should be conducted as well as its toxicity should be determined to ascertain its safety.

\section{References}

[1] Dawood, E.; Tazkret, Oli. In: El-Halaby and Co., Cairo, 1. Friedman, M., R. P. Henika and E. R. Mandrell (2002) Bactericidal activities of plant essential oils and some of their isolated constituents against Campylobacter jejuni, Escherichia coli, Listeria monocytogenes, and Salmonella enterica. J. Food Protect. 65: 1545-1560.

[2] Muhammad, A. S.; Mohammed, I. U.; Ameh, M.; Bello, I.; Haliru, B. S.; Bagudo, H. A. and Sanda A. S. (2018). Isolation and identification of fungi associated with the spoilage of sweet orange (Citrus sinensis L) and banana (Musa sapientum L) in Sokoto Metropolis. J Appl Biotechnol Bioeng. 5 (3): 176-186. DOI: 10.15406/jabb.2018.05.00135.

[3] Mbah, EN.; Okeke, M. N. and Attah, A. J. (2018). Strategies for Enhancing Production of Citrus among Small-Scale Farmers in Benue State, Nigeria. Inter. J. Res. Studies Agric Sci. 4 (4): 25-28. DOI: http://dx.doi.org/10.20431/24546224.0404004 .

[4] FAO. (2006). Statistical Database. Available from: http://faostat.fao.org/site/567/default.aspx\#ncor. Accessed on $8^{\text {th }}$ June, 2017.

[5] Rafiq, S.; Kaul, R.; Sofi, S. A.; Bashir, N.; Nazir, F.; and Nayik, G. D. (2018). Citrus peel as a source of functional ingredient: A review. J Saudi Society Agric Sci. 17 (4): 351358. https://doi.org/10.1016/j.jssas.2016.07.006.

[6] Bensalem P. A. (2006). Viable herbal solutions. http://www.manta.com/c/mm 4nrs1 viableherbalsolutions. Accessed on $6^{\text {th }}$ May, 2017.

[7] Magwa, M. L., Gundidza, M. and Gweru, N. (2006). Chemical composition and biological activities of essential oil from the leaves of Sesuvium portulacastrum. J. Ethnopharmacol. 10: 85-89.

[8] Magiatis, P.; Melliou E.; and Skaltsounis, A. L. (1999). Chemical composition and antibacterial activity of essential oils of Pistacia lentiscus var. chia. Planta Medica. 65 (8): 749-752.

[9] Martins, A. P.; Salgueiro, L. R. and Goncalves, M. J. (2000). Antibacterial activity and chemical composition of the bark oil of Croton stelluifer, and endemic species from St. Tome and Principy. Planta Medica. 66 (7): 647-650.

[10] Filipowicz, N.; Kaminski, M. and Kurlenda, J. (2003). Antibacterial and antifungal activity of juniper berry oil and its selected components. Phytotherapy Res. 17: 227-231.

[11] Venkatsen, C; Chidambaram, M.; and Singh. A. P. (2005). 3aminopropyltriethoxysilylfunctionalized na-al-mcm-41 solid base catalyst for selective preparation of 2-phenylpropionitrile from phenylacetonitrile. Appl Cat. 292: 344-353.

[12] Chen, J.;. Lu, M. and Jing, Y. (2006). The synthesis of 1carvone and limonene derivatives with increased antiproliferative effect and activation of erk pathway in prostate. cancer cells. Bioorganic Medicinal Chem. 14 (19): 6539-6547.

[13] Erazo, S.; Delporte, C. and Negrete, R. (2006). Constituents and biological activities of Schinus polygamus. J. Ethnopharm. 107: 305-400.

[14] Jidong, S. (2007). D-Limonene: Safety and Clinical Applications Alter Med Rev. 12: 3-264.

[15] Vivek, K.; Nandin, R.; Shashadhara, S.; Anitha, S.. (2010). Anti-typhoid activity of aqueous extract of fruit peel Citrus sinensis (L). Inter. J. Pharm. Res. Dev. 2 (9): 31. 26.

[16] Alams, K.; Skaug, N. and Ahmad, I. (2005). An in vitro antimicrobial comparison of miswak extract with commercially available non-alcohol mouth rinses. Intern. J. Den. Hyg. 3 (1): 18-24.

[17] Okwu, D. E.; Awurum, A. N. and Okoronkwo, J. I. (2007). Phytochemical composition and in vitro antifungal activity screening of extracts from Citrus plants against Fusarium oxysporum of Okra plant (Hibiscus esculentus). Afri Crop Sci Conference Proceedings. 8: 1755-1758.

[18] Svoboda, K. P. and Greenaway, R. I. (2003). Lemon scented plants. Inter J. Aromatherapy. 13 (1): 23-32. http://dx.doi.org/10.1016/S0962 4562(03)00048-1.

[19] Toscano-Garibay, J. D.; Arriaga-Alba, M.; Sánchez-Navarrete, J.; Mendoza-García, M.; Flores-Estrada, J. J.; MorenoEutimio, M. A.; Espinosa-Aguirre, J. J.; González-Ávila, M. and Ruiz-Pérez, N. J. (2017). Antimutagenic and antioxidant activity of the essential oils of Citrus sinensis and Citrus latifolia. Scientific Reports. 7: 11479 | DOI: 10.1038/s41598017-11818-5.

[20] Shabnam, J.; Ayesha, J.; Shaista, M. K; Saeed., Z.; Siddiquis, S. Z. and Rauf, A. (2014). Phytochemistry, GC-MSAnalysis, Antioxidant and Antimicrobial Potential of Essential Oil From Five Citrus species. J. Agric. Sci. 6 (3): 1916-9752.

[21] Yang, S. A.; Jeon, S. K.; Lee, E. J.; Shrim, C. H. and Lee, I. S. (2010). Comparative study of the chemical composition and antioxidant activity of Essential oil and their components. Natural Prod Res. 24: 140-151.

[22] Dhekra, T.; Ahlem, H. A.; Faten, B, and Fethi, Z. (2014). Antioxidant and Antimicrobial Activities of Essential Oils and Methanolic Extracts of Tunisian. Citrus aurantium. J. Environ. Sci. Toxicol. Food Technol. 8: 2319-2399.

[23] Di Renzo, L.; Gualtieri, P.; Romano, L.; Marrone, G.; Pujia, A. A.; Perrone, M. A.; Aiello, V.; Colica, C. and De Lorenzo, A. (2019). Role of personalized nutrition in chronicdegenerative diseases. Nutrients. 11 (8): 1707.

[24] Jayasri, M. A.; Mathew, L. and Radha, A. (2009). A report on the antioxidant activities of leaves and rhizomes of Costus pictus D. Don. Inter J. Integrative Biol. 5 (1): 20-26.

[25] Dhiman, A.; Nanda, A.; Ahmed, S. and Narasimham, B. (2012). In vitro antimicrobial status of methanol extract of Citrus sinensis Linn. Fruit peel. Chron. Young Sci. 3 (3): $204-$ 208. 
[26] Afroja, S.; Falgunee, F. N.; Jahan, M. M.; Akanda, K. M.; Mehjabin, S. and Parvez, G. M. M (2017). Antibacterial activity of different Citrus fruits. Specialty J. Med. Res. Health Sci. 2 (1): 25-32.

[27] Ayoola, G. A.; Johnson, O. O.; Adelowotan, T.; Aibinu, I. E.; Adenipekun, E.; Adepoju-Bello, A. A.; Odugbemi, T., O. (2007). Evaluation of the chemical constituents and the antimicrobial activity of the volatile oil of Citrus reticulate fruit (Tangerine fruit peel) from South West Nigeria. Afri. J. Biotech. 7 (13): 2227-2231.

[28] Sofowora A (1993). Medicinal Plants and Traditional Medicine in Africa. Spectrum Books Ltd., Ibadan, Nigeria. pp 191-289.

[29] Trease, G. E., and Evans, W. C. (1989). Pharmacognosy, 11th edn., Bailliere Tindall, London. pp. 45-50.

[30] Harborne, J. B. (1973). Phytochemical Methods. Chapman and Hall Ltd., London. pp. 49-188.

[31] Obidi, O. F.; Adelowotan, A. O.; Ayoola, G. A.; Johnson, O. O.; Hassan, M. O. and Nwachukwu, S. C. U. (2013) Antimicrobial Activity of Orange Oil on Selected Pathogen. The Inter. J. Biotechnol. 3 (6): 113-122.
[32] Ebrahimzadeh, M. A.; Hosseinimehr, S. J.; Hamidinia, A and Jafari M. (2008). Antioxidant and free radical scavenging activity of Feijoasal lowiana fruits peel and leaves. Pharmacologyonline, 1: 7-14.

[33] Forbes, B. A.; Sahm, D. F. and Weissfeld, A. S. (2007). Ailey and Scotts' Diagnostic Microbiology 12th edition, Elsevier China. pp 252-259.

[34] NCCLS. (2002). Methods for dilution antimicrobial susceptibility tests of bacteria that grow aerobically. Approved Standard M100-S12. Wayne. PA, NCCLS.

[35] Prescott, L. M.; Harley, J. and Klein, D. A. (2002). Microbiology, 5th. ed, McGraw-Hill New York, pp. 809-811.

[36] Madunagu, B. E.; Udo, S. E.; Umana, E. J. and Markson, A. A. (2005). Exploitation of phanerogamic parasites and epiphytic plants for their medicinal values. Nigerian J. Plant Protect. 22: 17-23.

[37] Andrea, V.; Nadia, N.; Teresa, R. M. and Andrea, A. (2003). Analysis of some Italian lemon liquors (Limoncello). J Agric. Food Chem. 51 (17): 4978-4983. 